\title{
Growth and Bone Age of Juvenile Diabetics
}

\author{
NIGEL EVANS, * V. P. ROBINSON, $†$ and J. LISTER \\ From Wexham Park Hospital, Slough; King Edward VII Hospital, Windsor; and St. Mary's Hospital, London
}

\begin{abstract}
Evans, N., Robinson, V. P., and Lister, J. (1972). Archives of Disease in Childhood, 47, 589. Growth and bone age of juvenile diabetics. The growth of a group of juvenile diabetics on restricted carbohydrate diets has been studied using standardized techniques. Most patients were distributed between the 10th and 90th centiles for height, weight, bone age, and subscapular skinfold thickness. There was, however, a statistically significant tendency for females to be above average in weight and for both sexes to have thicker than normal skinfolds. A duration of diabetes of over 6 years led to significant underheight in boys and girls in the presence of normally distributed bone ages. Boys who had had diabetes for less than 6 years were found to have advanced bone ages.
\end{abstract}

There are published reports of many series of diabetics in which growth has been recorded with variable results. There have been few reports on growth of British diabetic children using standardized techniques. In the present study we have assessed growth by anthropometry on juvenile diabetics at special outpatient visits. Skeletal maturity was also recorded. The methods of Tanner and Whitehouse were used throughout and the results recorded on their centile charts (Tanner and Whitehouse, 1962; Tanner, Whitehouse, and Healy, 1962; Tanner, Whitehouse, and Takaishi, 1966). Subcutaneous fat was assessed in the subscapular region only, as many children received insulin injections in the upper arm.

\section{Patients}

Fifty-five male and 49 female juvenile diabetics have been studied. All of these patients developed diabetes before the age of 15 years. Their average age at the time of the study was 15.8 years with a range from $3 \cdot 0$ to $45 \cdot 5$. There were 40 boys under 19 years of age and 27 girls under 17. (19 and 17 years were taken as the ages of skeletal maturity in boys and girls, respectively.) The average duration of diabetes for all male patients was 6.8 years and for all female patients 9.7; for both sexes the duration ranged from 0.2 to 32.0 years. All the patients were on restricted carbohydrate diets and the majority were on twice-daily injections of soluble insulin.

Received 8 December 1971.

^Present address: Guy's Hospital, London S.E.1.

†Present address: Queen Charlotte's Maternity Hospital, London

\section{Results}

Height (Fig. 1 and Table I). Most patients were distributed between the 10th and 90th centiles. There was a tendency for more males of all ages than females of all ages to lie below the 50th centile, but this was not statistically significant.

TABLE I

Distribution of All Patients Around the 50th Centile for Height, Weight, and Subscapular Skinfold Thickness

\begin{tabular}{l|c|c|c|c}
\hline & Sex & $\begin{array}{c}>\text { 50th } \\
\text { Centile }\end{array}$ & $\begin{array}{c}<50 \text { th } \\
\text { Centile }\end{array}$ & Significance \\
\hline Height & M & 19 & 32 & NS \\
Weight & F & 25 & 21 & NS \\
Subscapular & M & 25 & 25 & NS \\
skinfold & F & 31 & 15 & $5 \%$ level \\
& M & 32 & 17 & $5 \%$ level \\
& F & 35 & 11 & $1 \%$ level \\
\hline
\end{tabular}

Weight (Fig. 2 and Table I). Again most patients were distributed between the 10th and 90th centiles. More girls of all ages lay above the 50 th centile than below it (significant at 5\% level), while the boys were more equally distributed. There was no difference in the height or weight attainment of either sex with regard to diabetic control as judged by blood sugar estimations taken at clinic visits.

Subscapular skinfold (Fig. 3 and Table I). In both sexes there was a marked tendency to lie 

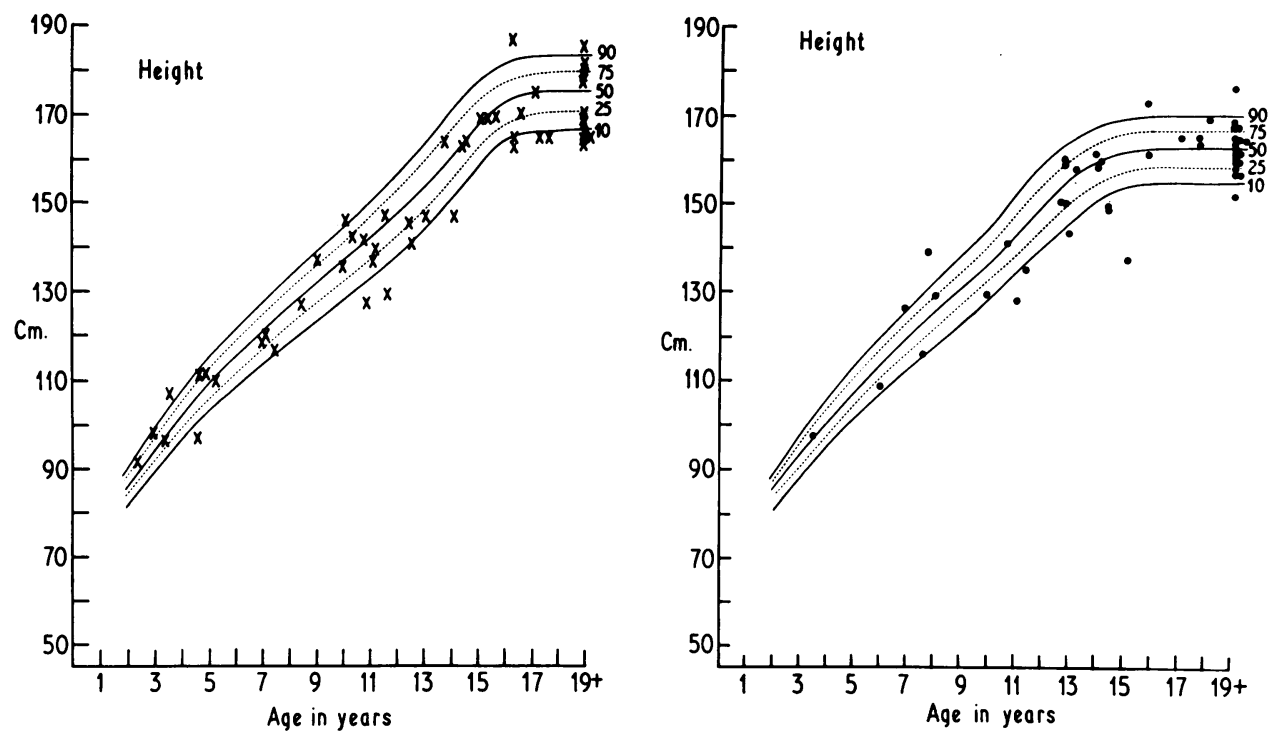

Fig. 1.-Centile chart for height, $\times$ males, $\bullet$ females.

above the 50th centile (significant at $5 \%$ level for males and $1 \%$ level for females) but within the normal range.

Bone age (Fig. 4 and Table II). Boys in general tended to have advanced bone ages. More boys lay above the 50th centile than below it (significant at $1 \%$ level).

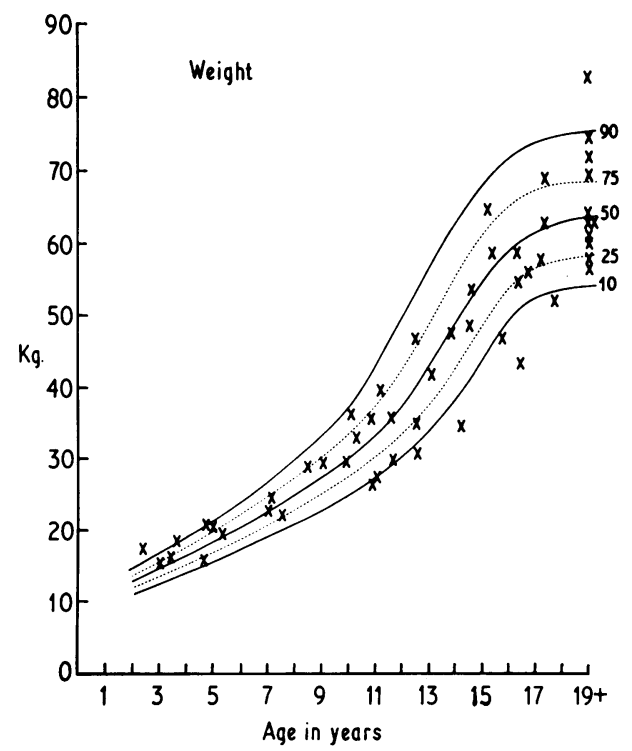

Age of onset and duration of diabetes (Fig. 4). There was a negative association between height and duration. Rather than a linear regression there appeared to be a 'cut off' point between 6 and 7 years' duration. An arbitrary decision to dichotomize at 6 years was taken because this age gave a better numerical distribution of children in the various groups. Both boys and girls with a

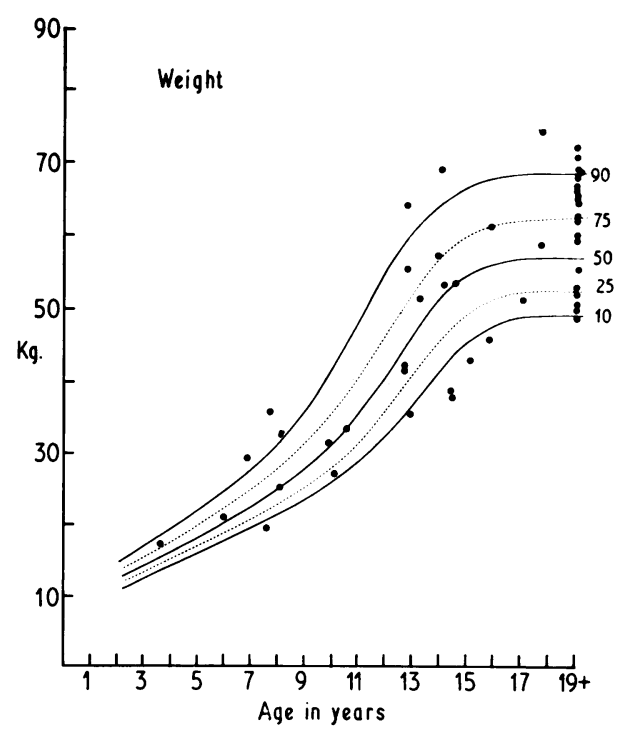

Fig. 2.-Centile chart for weight, $\times$ males, $\bullet$ females. 

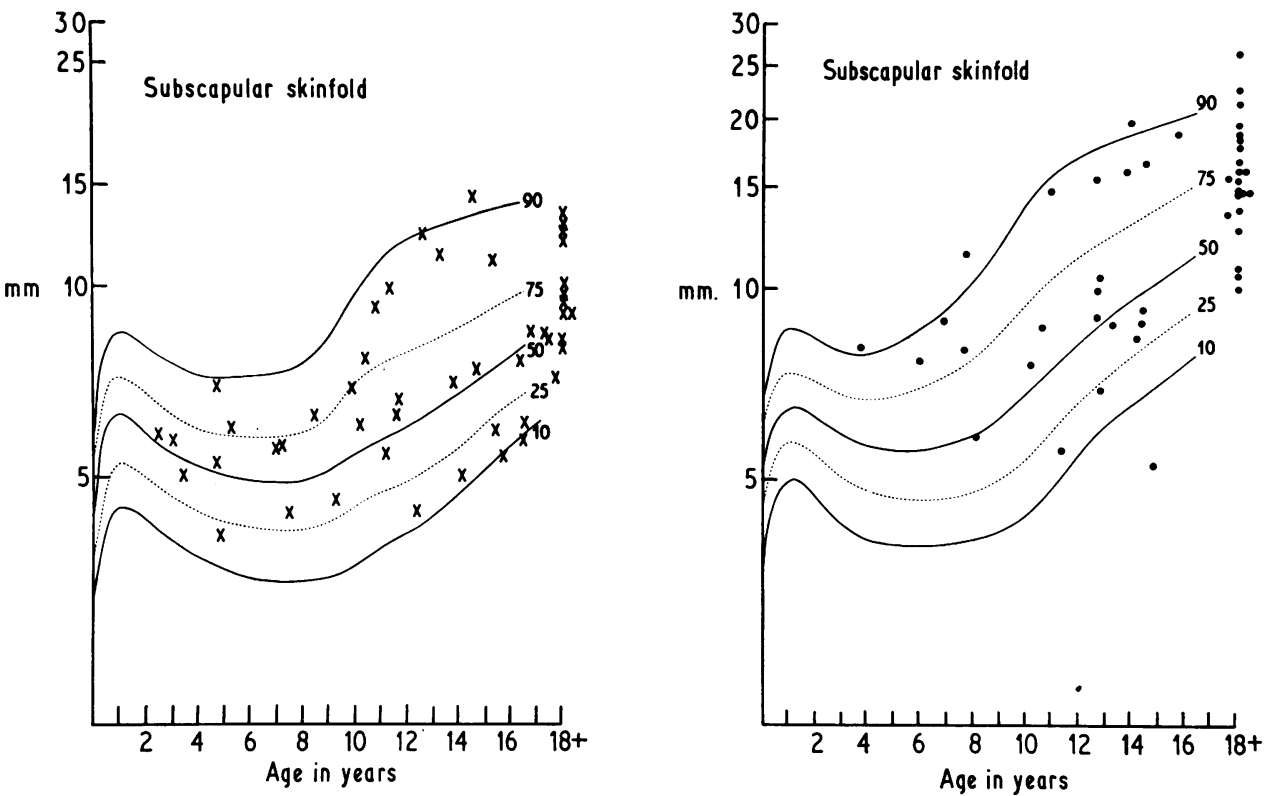

Fig. 3.-Centile chart for subscapular skinfold thickness, $\times$ males, $\bigcirc$ females.

duration of diabetes of 6 years or more tended to be below average in height (significant at $0.1 \%$ level). Children with a duration of less than 1 year did not tend to be overheight (numbers in this group were small).

There was no significant alteration of weight with duration of diabetes.
Boys with a duration of diabetes under 6 years had an advanced bone age (significant at $0.1 \%$ level). There were only 4 boys below the 50th centile for skeletal age and 23 above it. Girls who had had diabetes for less than 6 years had expected values for bone age. Boys and girls with a duration of diabetes over 6 years also had normal bone

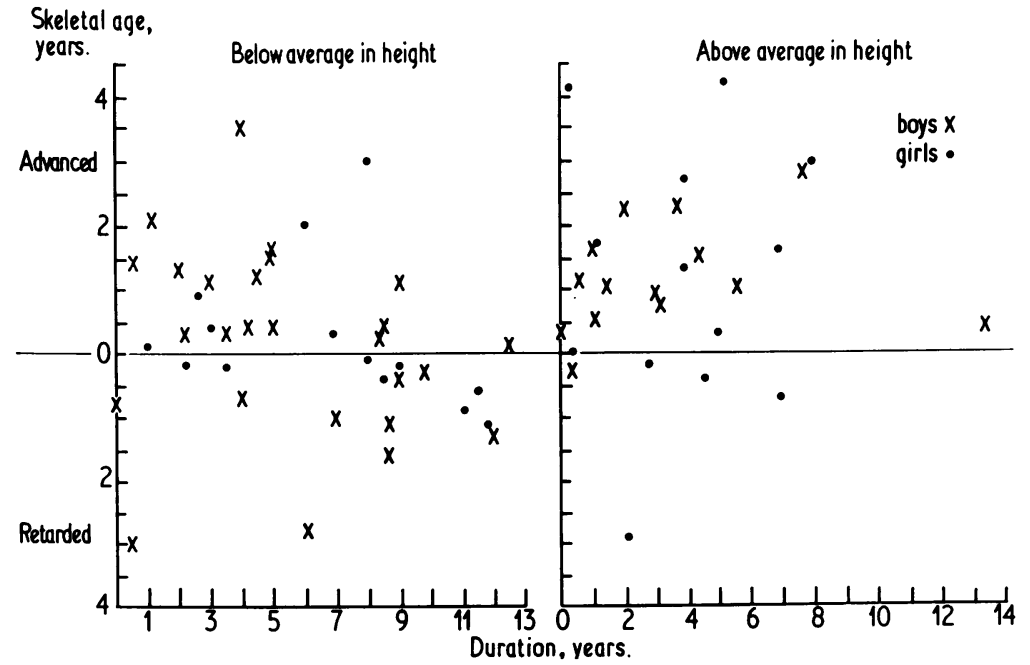

FIG. 4.-Duration of diabetes in boys under 19 years and girls under 17 years showing relation with height and skeletal age. 
TABLE II

Distribution of Children Around the 50th Centile for Bone Age

\begin{tabular}{l|c|c|c}
\hline \multicolumn{1}{c|}{$\begin{array}{c}\text { Sex and } \\
\text { Actual Age }\end{array}$} & $\begin{array}{c}>50 \text { th } \\
\text { Centile }\end{array}$ & $\begin{array}{c}<50 \text { th } \\
\text { Centile }\end{array}$ & Significance \\
\hline Boys under 19 years & 30 & 11 & $1 \%$ level \\
Girls under 17 years & 15 & 11 & \begin{tabular}{c} 
NS \\
\hline
\end{tabular}
\end{tabular}

^Age of skeletal maturity.

ages in the presence of below-normal heights.

Age of onset had no bearing on subsequent weight, height, or bone age.

\section{Discussion}

From the preinsulin era there were few reports of the growth of juvenile diabetics. In Joslin's series (Joslin, Root, and White, 1925), out of 20 patients observed for 2 years, only one gained in height. With the introduction of insulin, growth spurts following treatment were recorded in spite of diets low in calories and carbohydrates (Joslin et al., 1925). By providing more calories and adequately controlling the diabetes, normal growth rates were in general obtained (Boyd and Kantrow, 1938; Brown and Thompson, 1940; Jackson and Kelly, 1946), though this was not a universal finding (Fischer, 1929; Rabinowitch and Bazin, 1929; Beal, 1948). In a large series of 1407 juvenile diabetics reported by Wagner, White, and Bogan (1942), $118(8.3 \%)$ were stunted. In more recent years Berquist (1954) and Leopold (1960) have shown that diabetic children on free diets usually lay between the 10th and 90th centiles for height. However, it has also been noted that diabetics, especially males, have a lower than normal height distribution (Berqvist, 1954; Larsson and Sterky, 1962; Pond, 1970). A tendency to overheight at the time of diagnosis has also been observed (Rabinowitch and Bazin, 1929; Pond, 1970).

We have shown again that most juvenile diabetics lay between the 10th and 90th centiles for height. Though there was a tendency for more boys than girls to lie below the 50th centile, this was not statistically significant. Poor diabetic control has been associated with poor growth attainment (Berqvist, 1954; Larsson and Sterky, 1962; Pond, 1970). There was no significant relation in our series between height and degree of diabetic control attained. Similar results were reported by Craig (1970). A duration of diabetes of more than 6 years, however, was found to cause a significant reduction in height in both sexes. We could not confirm that juvenile diabetics were overheight at the time of diagnosis.
The weights of juvenile diabetics have attracted much less attention than their heights. Some authors have commented on a tendency for girls to be overweight (Fischer, 1929; Wagner et al., 1942) and this was confirmed. Boys have been noted to be generally underweight (Fischer, 1929), however, we found the boys' weights to be equally distributed around the mean for controls. Sterky (1967) states that skinfold thickness is increased in diabetics of all ages and this finding is confirmed in the present series.

Wagner et al. (1942) reported general retardation of bone age in children with diabetes. Bogan (1940) found retardation in $60 \%$ of males and $51 \%$ of females. She also noted that the longer the duration of diabetes the greater the tendency to retardation. In other series, though some children had accelerated and some retarded bone ages, the majority were within normal limits (Hernberg and Heikel, 1951). Atlas controls were used in all these series. Craig (1970), using the Tanner standards, found a progressive delay in bone age and height age in all children. In contrast we have shown that boys in general have a significantly advanced bone age. When duration of diabetes is taken into account, it becomes apparent that it is those boys with a duration of under 6 years who have advanced bone ages. Girls with a duration of under 6 years did not show this advance. As the number of girls was small; it is possible that the apparent difference between the sexes was not real. Further longitudinal studies are proceeding to elucidate this problem. Patients with diabetes lasting more than 6 years have normally distributed bone ages but are significantly shorter than expected.

Our present state of knowledge allows only speculation as to the metabolic causes of the initial advance in bone age (at least in males), and the later fall (to normal values) correlated with a fall in height and increase in skinfold thickness. Juvenile diabetics and their parents can, however, be reassured that their diabetes is unlikely to seriously affect their growth.

We thank Dr. J. Rubie and Dr. A. B. Donnison, for referring patients; Professor J. M. Tanner of the Institute of Child Health for helpful advice and criticism; Dr. Z. Abbas who helped to collect some of the early data; Dr. K. Woodcock and Dr. R. Drummond who are continuing a longitudinal study of the patients; Miss E. Fell for expert statistical advice; the Department of Radiology at Wexham Park Hospital for the hand $x$-rays; and Miss S. Robinson for the graphs.

\section{REFERENCES}

Beal, C. K. (1948). Body size and growth rate of children with diabetes mellitus. Fournal of Pediatrics, 32, 170. 
Berqvist, N. (1954). The growth of juvenile diabetics. Acta Endocrinologica (Kobenhavn), 15, 133.

Bogan, I. K. (1940). Hands and wrists of the diabetic child: a roentgenologic study. American fournal of Diseases of Children, $59,805$.

Boyd, J. D., and Kantrow, A. H. (1938), Retardation of growth in diabetic children. American fournal of Diseases of Children, $55,460$.

Brown, G. D., and Thompson, W. H. (1940). The diabetic child: an analytic study of his development. American fournal of Diseases of Children, 59, 238.

Craig, J. O. (1970). Growth as a measurement of control in the managernent of diabetic children. Postgraduate Medical Fournal, 46, Suppl. (Sept.), 607.

Fischer, A. E. (1929). The treatment of juvenile diabetes. American fournal of Diseases of Children, 38, 323.

Hernberg, C. A., and Heikel, P. E. (1951). The skeletal age in diabetic children. Acta Paediatrica, 40, 486.

Jackson, R. L., and Kelly, H. G. (1946). Growth of children with diabetes mellitus in relationship to level of control of the disease. fournal of Pediatrics, 29, 316.

Joslin, E. P., Root, H. F., and White, P. (1925). Growth, development and prognosis of diabetic children. Fournal of the American Medical Association, 85, 420.

Larsson, Y., and Sterky, G. (1962). Long-term prognosis in juvenile diabetes mellitus. Acta Paediatrica, 51, Suppl. 130.
Leopold, R. (1960). Erkrankungsalter und Wachstumsverlauf beim jugendlichen Diabetes mellitus. Helvetica Paediatrica Acta, 15, 336.

Pond, H. (1970). Some aspects of growth in diabetic children. Postgraduate Medical fournal, 46, Suppl. (Sept.), 616.

Rabinowitch, I. M., and Bazin, E. V. (1929). A statistical study of the rate of skeletal growth in juvenile diabetes. Archives of Disease in Childhood, 4, 125.

Sterky, G. (1967). Growth pattern in juvenile diabetes. Acta Paediatrica Scandinavica, 56, Suppl. 177, 80.

Tanner, J. M., and Whitehouse, R. H. (1962). Standards for subcutaneous fat in British children. British Medical fournal, 1, 446.

Tanner, J. M., Whitehouse, R. H., and Healy, M. J. R. (1962), A New System for Estimating Skeletal Maturity, from the Hand and Wrist, with Standards Derived from a Study of 2600 Healthy British Children. International Children's Centre, Paris.

Tanner, J. M., Whitehouse, R. H., and Takaishi, M. (1966). Standards from birth to maturity for height, weight, height velocity, and weight velocity: British children, 1965. Parts I and II. Archives of Disease in Childhood, 41, 454 and 613.

Wagner, R., White, P., and Bogan, I. K. (1942). Diabetic Dwarfism. American fournal of Diseases of Children, 63, 667.

Correspondence to Dr. J. Lister, Postgraduate Medical Centre, King Edward VII Hospital, Windsor, Berks. 